dan blijkt, dat bij een geschil tusschen den M. v. F. en een ambtgenoot. niet langer de Algemeene Rekenkamer wordt ingeschakeld, doch de Ministerraad. Voorts kunnen beide partijen een geschil voordragen zij het op andere gronden - en moet thans, in tegenstelling met vroeger, in het geschil worden beslist en wel door het Kabinet.

Als aangenomen mag worden, dat de wetswijziging definitiel is, zien we, dat de C.W. naast de A.R. en den M. v. F. thans mede den Ministerraad invloed toekent bij de wijze van besteding van 's Lands gelden, zij het op meer passieve wijze. Ik ben van meening, dat 's Lands financiën daarmede gebaat zullen zijn en de eenheid van begrooting daardoor bevorderd zal worden. Toch zie ik ook eenige bezwaren.

Volgens de vervallen regeling werd van een niet opgelost geschil tusschen den M. v. F. en een ambgenoot - zie hierboven - door eerstgenoemde kennis gegeven aan de Algemeene Rekenkamer. Ongetwijfeld mag worden aangenomen, dat dit College van dit geschil melding zou maken in zijn Verslag (art. 59 C.W.) aan de Staten-Generaal, waardoor het aan de openbaarheid wordt prijs gegeven. Thans wordt het geschil als het ware binnenkamers afgedaan en zal als regel ervan niets naar buiten bliiken. Dit is, naar ik meen, een stap achteruit in het contrôlesysteem.

Vervolgens zal n.m.m. de volgende complicatie zich kunnen voordoen. Stel een geschil wordt in den Ministerraad beslist ten ongunste van den M. v. F. Stel voorts, dat de Volksvertegenwoordiging - afgezien of zij al dan niet van het geschil kennis nam - het punt van beleid van den minister, dat oorzaak van het geschil was, niet aanvaardt. Welke zijn nu de gevolgen met betrekking tot den regel „De Minister is verantwoordelijk"? De betrokken bewindsman zal zich gedekt voelen door de beslissing van het Kabinet. Zegt men, de Ministerraad is verantwoordelijk aannemende, dat zulks mogelijk zou zijn — dan worden daarmede óók getroffen de M. v. F. en mede die ambtgenooten, welke hem steunden, dus juist degenen van den Raad, die in den geest van de Volksvertegenwoordiging handelden.

Ten slotte blijft mijn reeds bij de oude regeling naar voren gebracht bezwaar onverkort bestaan, n.l. alleen geschillen van meer belangrijken aard zullen worden opgelost op de door art. 36, 3e lid aangegeven wijze.

\title{
VORMT HET EIGENDOM VAN DUITSCHE MERKEN EEN WAARDEBEZIT VOOR DEN NEDERLANDSCHEN STAAT?
}

$\mathrm{Na}$ de algeheele bevrijding van Nederland zijn alle vermogenswaarden van Duitschers in Nederland verbeurd verklaard en aan den Nederlandschen Staat toegevallen. Tot deze vermogenswaarden behooren o.m. Duitsche merken en octrooien.

Wij willen in de hierna volgende beschouwingen uitsluitend aan de Duitsche merken aandacht besteden en de vraag tot onderwerp van bespreking maken, wat met deze merken moet worden gedaan.

Het Departement van Handel en Nijverheid heef $t$ een commissie uit het bedrijfsleven benoemd om in deze aangelegenheid van advies te dienen. Het bedrijfsleven zal het ongetwijfeld op prijs stellen, dat het op deze wijze in de gelegenheid wordt gesteld op dit vraagstuk, via het uitbrengen van advies, invloed uit te oefenen.

Reeds uit het feit, dat het Departement het noodig heeft geoordeeld 
voor deze aangelegenheid een commissie van advies te benoemen, blijkt dat de zaak niet zoo eenvoudig is als zij bij oppervlakkige waarneming schijnt.

Aangezien wij kennis hebben kunnen nemen van de notulen van de kortelings gehouden bespreking dezer commissie, is het ons in het hierna volgende mogelijk mede de markante punten uit de plaats gevonden gedachtenwisseling op te nemen.

Een goed ingevoerd handels- of fabrieksmerk bezit waarde. Het is, zoo lezen wij in de notulen, in zekeren zin geaccumuleerde goodwill, mede ontstaan door een vaak kostbare reclamecampagne. Het eigendom dezer merken is nu toegevallen aan den Nederlandschen Staat en het is de taak van het Departement een zoodanig samenstel van maatregelen te treffen. dat dit merkenbezit de Nederlandsche gemeenschap op de beste wijze zal dienen.

De critische vraag is dus: Welke maatregelen moeten worden getroffen, opdat dit inderdaad geschiedt?

De overheid heeft hierbij de keus tusschen twee methoden:

a. het merk kan ter beschikking worden gesteld van het Nederlandsche bedrijfsleven. De wijze waarop kan een afzonderlijk onderwerp van studie zijn.

b. het merk wordt niet ter beschikking gesteld van het Nederlandsche bedrijfsleven, d.w.z. de merken worden uit de circulatie genomen door het gebruik van deze merken te verbieden.

Het blijkt, dat beide mogelijkheden in de commissie zijn besproken, waarom het interessant is samen te vatten, welke argumenten hierbij naar voren kwamen.

Besproken werd het merk weer in bedrijf te stellen door verkoop aan den meest biedende. Hierbij werd opgemerkt, dat goede bedrijven aan merken van andere bedrijven geen behoefte hebben, omdat zij reeds over eigen goede merken beschikken.

Het is dan ook waarschijnlijk, dat deze merken, zoo zij zouden worden verkocht, zouden worden verworven door bedrijven, die er in het verleden niet in geslaagd zijn een eigen merk van eenige reputatie op te bouwen. Verkoop van Duitsche merken zou dus den bonafiden merkartikelfabrikant kunnen schaden en in zekeren zin voor hem een oneerlijke concurrentie scheppen.

Daarom kwamen sommige leden van de commissie tot de conclusie, dat de Staat niet tot verkoop van Duitsche merken moet besluiten, maar deze merken niet meer moet vrijgeven; zij moeten worden geblokkeerd en het onvervreemdbaar bezit van den Nederlandschen Staat blijven. Deze leden zijn dus voorstanders van de tweede methode. Dit beteekent, dat zij uit de circulatie worden genomen en dientengevolge voor de gemeenschap geen waarde bezitten. Zij zouden eerst waarde krijgen, wanneer de Nederlandsche Staat t.z.t. zou besluiten, — indien weer import van Duitsche producten mogelijk is - de Duitsche merken aan de vroegere eigenaren tegen betaling van een zekere som gelds te verkoopen. Ook tegen dezen verkoop in de toekomst hebben sommige leden bezwaar, omdat op deze wijze de Duitsche industrie haar voorsprong weer terug zou winnen, voor zooverre zij deze in het verleden bezat door het werken met goed bij het publiek ingevoerde merken.

Wanneer de Duitsche industrie in detoekomst haar merken niet zou terug kunnen koopen, zou zij genoodzaakt worden opnieuw haar markt in Nederland op te bouwen en hierdoor zich een zekere handicap zien toegewezen in den concurrentiestrijd. 
Andere leden hebben echter gewezen op de schade, welke door deze maatregel van overheidswege wordt toegebracht aan den importeur van het Duitsche product. Het valt toch niet te miskennen, dat in vele gevallen het merk hier in Nederland grootendeels door den importeur is opgebouwd en dat de groote bedragen, welke voor den opbouw van een nationaal merk noodig waren door den importeur zijn gefourneerd. Zou men dan ook besluiten deze merken te bevriezen, d.w.z. van overheidswege deze merken uit de circulatie te nemen, dan zouden deze importeurs hierdoor ernstig worden gedupeerd. De maatregel, die Duitsche belangen moet treffen, zou hier een reëel Nederlandsch belang schaden.

Wanneer men echter zou besluiten in deze gevallen het merk niet te blokkeeren en ter beschikking van importeurs te laten, zal het zonder meer duidelijk zijn, dat men hiermede de deur opent, waardoor velen binnen glippen om zich op deze wijze aan blokkeering van overheidswege te onttrekken.

Het zal toch in de practijk zeer moeilijk zijn na te gaan in welke mate de importeur uit eigen beurs de offers heeft gebracht om het merk op te bouwen. Het zal thans onmogelijk zijn vast te stellen in welke mate door den Duitschen fabrikant in het verleden, direct of indirect, bijgedragen is aan den opbouw van het merk hier te lande.

Daarenboven zou men dan tevens een onderzoek in moeten stellen naar de draden welke tusschen importeur en fabrikant bestaan en naar de belangengemeenschappen, welke in het verleden zijn geschapen.

Wanneer men dan ook tot blokkeering van de Duitsche merken zour besluiten, zou men zeer bezwaarlijk aan de bezwaren van den Nederland- schen importeur tegemoet kunnen komen.

Tot zoover in het kort de punten, die tijdens de bespreking naar voren kwamen.

Het wil ons echter voorkomen, dat men in de commissie niet de critische vraag heeft gesteld, welker beantwoording in zekeren zin tot oplossing van het geheele vraagstuk leidt.

Deze vraag is naar onze meening:

Heeft het vrijelijk kunnen beschikken over Duitsche merken voor de Nederlandsche volkshuishouding waarde?

De commissie heeft deze vraag niet gesteld, omdat zij zonder meer van de veronderstelling uitging, dat de vraag een "open deur" was; dit bezit heeft natuurlijk waarde, zou de commissie hebben geantwoord, ware haar deze vraag voorgelegd.

Dit is echter naar onze meening allerminst vanzelfsprekend en het is: zeker de moeite waard te onderzoeken, waar die waarde in zou kunnen, bestaan.

Hiertoe is het noodig het kenmerk van een „,merk" op te sporen.

Waarom creëert de fabrikant van een artikel een ",merk"?

Niet alle artikelen, die een merk dragen, kunnen als merkartikel worden gekwalificeerd. Niet alleen het hechten van het merkteeken op of aan een bepaald artikel maakt dit artikel tot merkartikel. Het wordt eerst merkartikel, wanneer het artikel door den consument onderscheidend wordt behandeld: wanneer de fabrikant weet te bewerkstelligen, dat de consument aan zijn artikel de voorkeur geeft boven soortgelijke concur reerende artikelen. De consument moet een voorkeurs-oordeel voor ein bepaald merk uitspreken. Als dit het geval is, is het merkartikel geboren. Eerst dan kan men van merkartikelen spreken; eerst dan heeft het merkartikel voor den fabrikant waarde.

De consument vraagt naar bepaalde merken, omdat de ervaring hem

m a b blz. 154 
heeft geleerd, dat de artikelen, die onder deze merken worden gebracht, op de beste wijze aan zijn vraag voldoen. Hij heeft de prijzen en kwaliteiten van de verschillende concurreerende artikelen met elkaar vergeleken en tenslotte na vergelijking zijn keus gedaan. $Z_{i j n}$ voorkeur is, na min of meer grondig onderzoek, gevallen op een bepaald merkartikel. Hij zal dit merk blijven koopen, zoolang de kwaliteit en smaak blijven overeenkomen met de smaak, welke door hem in het verleden werd geconstateerd. Dit beteekent, dat het merk zooveel mogelijk van constante kwaliteit moet zijn, opdat het product den consument bij opeenvolgende aankoopen niet teleurstelt.

In de stabiliteit en kwaliteitsgarantie van het merkartikel is voor den consument de groote waarde gelegen. Hij weet zonder meer, wat hij koopt, wanneer hij een bepaald merkartikel kiest. Het behoeft geen betoog. dat dit voor hem van zeer groote waarde is.

Bij aankoop van merkartikelen schakelt hij in zekeren zin het kwaliteitsrisico uit.

De goodwill, welke voor den fabrikant van een merkartikel in een merk gelegen is, komt voort uit de band welke door het merk tusschen fabrikant en afnemer is geschapen. De fabrikant heeft zich door zijn merk van een zekere klantenkring verzekerd en hierin is nu juist de waarde van het merk voor dezen fabrikant. gelegen.

Uit deze analyse volgt naar onze meening een zeer belangrijke conclusie in verband met de door de overheid te treffen maatregelen ten aanzien van de Duitsche merken.

De waarde van het merk is verloren op hetzelfde moment, dat men het scheidt van het product, waaraan het gebonden is. Dientengevolge bezitten de Duitsche merken geen of weinig handelswaarde.

De Duitsche merken hadden een zekere goodwill, verworven door de Duitsche producten. De Nederlandsche consument heeft in het verleden ervaring met deze producten opgedaan en na onderzoek van de markt zijn keuze op bepaalde Duitsche producten d.w.z. op bepaalde Duitsche merken, laten vallen, hetzij op grond van de superieure kwaliteit, hetzij op grond van den in de concurrentieklasse lagen prijs. Worden de merken losgemaakt van de hierbij behoorende Duitsche producten, dan verliezen de merken voor den consument iedere beteekenis en hebben zij dientengevolge voor een fabrikant geen enkele waarde meer.

De consument kocht een bepaald merk, omdat hij wist een bepaald product hierdoor te verwerven.

Gaat men nu deze Duitsche merken hechten op Nederlandsche producten, dan misleidt men den consument, omdat het allerminst zeker is, dat deze Nederlandsche producten in alle opzichten aan de eischen voldoen, waaraan de betreffende Duitsche producten in het verleden voldeden. Men misleidt dientengevolge den consument in hooge mate, waarom het naar onze meening aan geen twijfel onderhevig is, dat de afnemer dit spoedig zal ervaren, hetgeen tot gevolg zal hebben. dat hij in de toekomst deze Duitsche merken niet meer zal koopen. Hij zal genoodzaakt worden opnieuw kwaliteit en prijs van concurreerende producten met elkaar te vergelijken om zijn keuze wederom te bepalen. Of dan de consument het Nederlandsche product met het oude Duitsche merk zal koopen, zal afhangen van de vraag of dit product in zijn prijsklasse in vergelijking met andere soortgelijke producten superieur is.

Het geval is zeer wel denkbaar, dat het voeren van Duitsche merken, waardoor men in zekeren zin een vlag voert, die de lading niet dekt, tengevolge van het feit, dat de consument bij eersten aankoop wordt teleur- 
gesteld, een ongunstige uitwerking op den consument zal hebben en hem veeleer van deze producten zal afstooten.

In dit geval heeft de fabrikant, die een Duitsch merk heeft gekocht, teneinde hiermede de afzet van zijn productie te pousseeren, in plaats van steun hinder van het Duitsche merk. Het merk bezit voor hem dan geen positieve, mar negatieve goodwill.

Deze analyse is echter van toepassing op producten, waarvan de consument in staat is de kwaliteit te beoordeelen, zoodat hij de kwaliteit van verschillende producten met elkaar kan vergelijken. Er zijn echter producten, b.v. in de pharmaceutische branche, waarbij de consument geheel afgaat op het merk en de voorkeur geeft aan bepaalde merken, hoewel deze producten kwalitatief in geen enkel opzicht verschillen van soortgelijke producten. In dit geval zou de consument het dus niet bemerken, wanneer het merk van den eenen producent op den andere overgaat. $\mathrm{Hij}_{\mathrm{ij}}$ al het echter wel weten, omdat het hem bekend is, dat Duitsche producten niet meer aan de markt komen. Hoe de consument zal reageeren op deze overdracht van merk bepaalt alsdan de handelswaarde van het merk. Blijft hij aan het merk trouw, dan kan het een hooge handelswaarde hebben.

De vraag is echter gerechtvaardigd, wat onze maatschappij als geheel gezien bij een dergelijke politiek, zelfs in dit geval, zou winnen. Is het dan niet beter de, door het wegvallen van den import van Duitsche producten, vrijgekomen afzet, of in verhouding tot ieders vóór-oorlogsch aandeel over de Nederlandsche producenten te verdeelen, of de onderlinge concurrentie deze verdeeling tot stand te laten brengen.

Wij komen dan ook tot de conclusie, dat de Duitsche merken thans in de Nederlandsche gemeenschap geen warde bezitten en dat geen schade wordt aangericht wanneer deze merken niet in circulatie worden gebracht.

Ter voorkoming van misverstand zij opgemerkt, dat duidelijk tusschen merken en octrooien moet worden onderscheiden.

Hetgeen hier ten aanzien van merken wordt beoogd, is zeker niet zonder meer van toepassing op het bezit van Duitsche octrooien en patenten.

Thans nog de vraag: Bezitten de Duitsche merken misschien t.z.t. "waarde" door verkoop aan Duitschland, wanneer weer de import van Duitsche producten plaats vindt?

Daarom zal men reeds thans de vraag onder oogen moeten zien, wat de Nederlandsche Regeering te doen staat, wanneer te gelegener tijd opnieuw Duitsche producten in Nederland zullen worden geimporteerd. De Duitsche merken zijn het eigendom geworden van den Nederlandschen Staat, zoodat deze producten zonder meer niet onder de oude merken mogen worden ingevoerd.

De mogelijkheid is geopperd deze merken dan aan de Duitsche producenten terug te verkoopen, zoodat hierdoor een min of meer belangrijk bedrag in de Nederlandsche Staatskas vloeit, welk bedrag te beschouwen zou zijn als tegemoetkoming in de door Nederland geleden oorlogsschade. Zoo aantrekkelijk deze handelwijze schijnt, dient men zich naar onze meening thans reeds terdege te realiseeren, dat de verkoop van Duitsche merken aan de vroegere eigenaren te gelegener tijd ongetwijfeld ernstige moeilijkheden van handelspolitieken aard met zich zal brengen.

Wanneer de Regeering het t.z.t. ook voor Nederland noodig en nuttig oordeelt Duitsche producten te importeeren, doet het merkwaardig aan, wanneer zij anderzijds de invoer van deze producten belemmert door het

$\mathrm{m} \mathrm{a} \mathrm{b}$ blz. 156 
den producenten slechts na betaling van min of meer belangrijke bedragen mogelijk te maken hun producten onder de oude merken te brengen.

Wanneer men de invoer niet wenscht, dient de Regeering een invoerverbod af te kondigen.

Wanneer men de invoer slechts onder beperkende bepalingen wenscht, kan men de oplossing zoeken in een min of meer belangrijk invoerrecht.

Wij gelooven echter niet, dat de Nederlandsche Regeering de buitenlandsche producten een handicap moet opleggen door hen te verbieden de oude merken te voeren, dan wel aan het voeren van oude merken een zekere belasting te verbinden. Want hierop komt het toch neer, wanneer men den fabrikant dwingt voor de verwerving van zijn oude merk een belangrijk bedrag te betalen.

Zou men de merken in het geheel niet ter beschikking stellen, dan zou men den fabrikant dwingen zijn artikel onder nieuwe merken in den handel te brengen. Ook het opleggen van deze handicap achten wij te gelegener tijd moeilijk doorvoerbaar. De consument moet opnieuw met de Duitsche merken kennis maken en ervaring op doen met de kwaliteit.

Wanneer de fabrikant het product onder het oude merk brengt, zal de afnemer op grond van zijn ervaring in het verleden onmiddellijk met kennis van zaken een keuze kunnen doen.

Daarenboven dwingt het merk den fabrikant van het te goeder naam en faam bekend staande merkartikel de kwaliteit uit het verleden zooveel mogelijk te benaderen; een zekere kwaliteitswaarborg voor den afnemer.

Het zou dus wel zeer ondoelmatig zijn deze kwaliteitswaarborg voor de Duitsche producten weg te nemen. Naar onze meening zal de Nederlandsche Regeering ongetwijfeld de Duitsche merken opnieuw moeten aanvaarden. Ook om deze reden komt het ons niet verstandig voor thans aan Nederlandsche fabrikanten toe te staan deze merken aan hun Nederlandsche producten te hechten. teneinde de verwarring te voorkomen, die hierdoor ongetwijfeld in de toekomst zal ontstaan.

\section{MEDEDEELING VAN HET NEDERLANDSCH INSTITUUT VAN ACCOUNTANTS.}

In de buitengewone algemeene vergadering van 15 Maart 1946 werden de volgende Heeren tot lid der Vereeniging benoemd:

A. W. Aarts, Tesselschadelaan 1, Aerdenhout.

C. H. Elbers, ec. drs., Vroenhof 433, Houthem (L).

P. C. Kaiser, Groest 57, Hilversum.

H. P. Krouwels, ec. drs., Kennemerplein 21, Haarlem.

\section{INGEKOMEN BOEKEN.}

Drs. A. M. Groot, Contrōle op Bedrijfsbeheer en Bedrijfsefficiency door Variabele Budgetteering. 4e druk. Uitgever J. Muusses, Purmerend, prijs $f 4,50$.

Drs. A. M. Groot, Moderne Kostprijsopvattingen, 2e druk. Uitgever J. Muusses, Purmerend, prijs $f$ 4,25.

Drs. A. M. Groot, Grondslagen van de Moderne Bedrijfsadministratie. le druk. Uitgever J. Muusses, Purmerend, prijs f 12,50.

Stichting Economisch Instituut voor den Middenstand, Onderzoek naar de rentabiliteit van het Rijwielbedrijf, 's-Gravenhage 1946.

Statistiek voor het Kruideniersbedrijf (XI), s-Gravenhage 1944.

Statistiek voor het Slagersbedrijf (X), 's-Gravenhage 1944. 